\title{
Rate of Absorption of Injected Nitrogen Bubbles in Molten Iron*
}

\author{
By Masamichi SANO, ,* Korehito KADOGUCHI*** and Kazumi MORI**
}

\section{Synopsis}

A study was made of the rate of absorption of injected nitrogen in molten iron. Nitrogen was injected into the melt through an immersed alumina nozzle of $0.1 \mathrm{~cm}$ in $1 . D$. and $0.3 \mathrm{~cm}$ in $O . D$. The immersion depth of the nozzle was $3.3 \sim 4.7 \mathrm{~cm}$. The gas flow rate was $1.17 \sim$ $1.67 \mathrm{Ncm}^{3} / \mathrm{min}$. The oxygen and sulfur concentrations in the melt were varied widely. During the nitrogen absorption experiment, the bubble formation time was measured by using a pressure pulse technique.

The rate data were compared with calculated results from a mixed control model of liquid-phase mass transfer and chemical reaction at the bubble-metal interface. Nitrogen absorption during bubble formation was taken into account in the model. From the comparison between calculation and experiment, the chemical reaction rate constant'was obtained. It is shown that the chemical reaction rate constant decreases with increasing $[\% \mathrm{O}]+[\% \mathrm{~S}] / 2$. The rate constant for the bubble interface roughly agrees with that for the free surface of melt.

\section{Introduction}

Techniques of submerged gas injection are playing an increasingly important role in high temperature metallurgical processes. To clarify various phenomena occurring in the processes, knowledge on the kinetics of interactions of injected bubbles and molten metals is essential. Previously, studies were made on the formation of bubbles from a single nozzle in mercury and molten silver, ${ }^{1)}$ and also in molten iron, ${ }^{2)}$ and on the deoxidation of molten silver by injecting argon into the melt. ${ }^{3)}$

The present study is concerned with the absorption rate of nitrogen injected into molten iron. The reaction mechanism is discussed on the basis of comparison between experiments and theoretical calculations from a mixed control model of liquid-phase mass transfer and chemical reaction at the bubble interface. Since the area of bubble-metal interface is required in the calculations, the frequency of bubble formation was measured in each absorption experiment. The measured frequency was also used to calculate the amount of absorbed nitrogen during the bubble formation.

As to the molten iron-nitrogen reaction, many studies were made on absorption and desorption through the free surface of melt. ${ }^{4-6)}$ However, the definite roles of liquid-phase mass transfer and chemical reaction in determining the rate have not yet been understood.

Several studies were made on the absorption of nitrogen injected into molten iron. ${ }^{7,8)}$ These studies, though extensive, lacked accurate measurement of the size of bubbles. The kinetics of molten iron- nitrogen reaction through the bubble interface were not fully understood.

Previously, the authors studied molten silveroxygen reaction by blowing reacting gas onto the melt $^{9)}$ and into the melt. ${ }^{3)}$ It was found that mechanism of the reaction through the free surface was different from that through the bubble interface. It is presumed that the difference is attributable to the different interfacial conditions. From this viewpoint, the rate-controlling mechanism of the molten ironnitrogen reaction through the bubble interface will be compared with that through the melt surface.

\section{Experimental}

The experimental apparatus is shown in Fig. 1. A Tammann furnace was used to melt electrolytic iron in a magnesia crucible of $38 \mathrm{~mm}$ in I.D. and $100 \mathrm{~mm}$ in height. On the surface of the melt a magnesia ring of $10 \mathrm{~mm}$ in I.D., $33 \mathrm{~mm}$ in O.D. and $7 \mathrm{~mm}$ in thickness was placed to reduce the free surface of the melt.

Figure 2 shows a schematic illustration of the gas supply train and nozzle. An alumina nozzle of $110 \mathrm{~mm}$ in length and an alumina pipe of $400 \mathrm{~mm}$ in length were connected and inserted in an alumina outer pipe. The tip of the nozzle was faced upward. The diameters of inner and outer pipes were $1.3 \mathrm{~mm}$ in I.D. and $3.5 \mathrm{~mm}$ in O.D., respectively. For

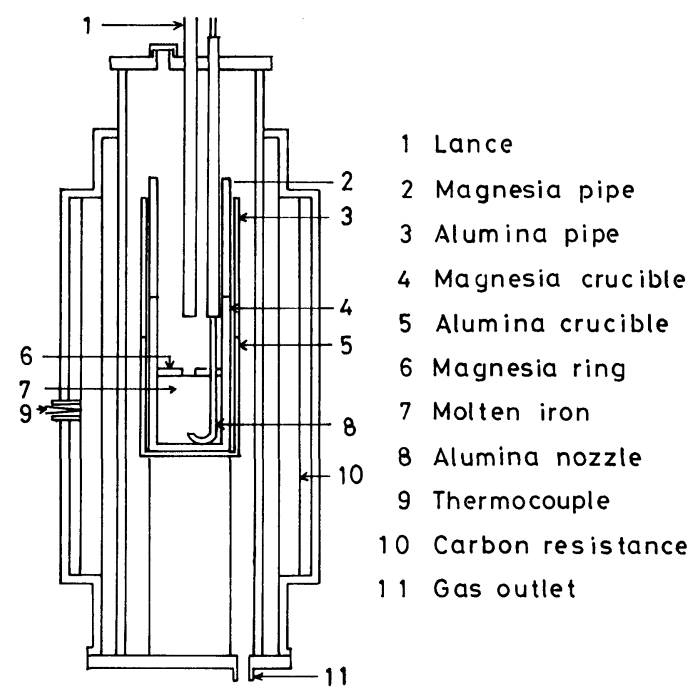

Fig. 1. Experimental apparatus.

\footnotetext{
* Presented to the 102nd ISIJ Meeting, October 1981, S860, at Kyoto-fu Chusho Kigyo Kaikan in Kyoto, and the 103rd ISIJ Meeting, April 1982, S184, at Tokyo Institute of Technology in Tokyo. Manuscript received March 19, 1984. (C) 1984 ISIJ

** Department of Metallurgy, Faculty of Engineering, Nagoya University, Furo-cho, Chikusa-ku, Nagoya 464.

*** Formerly Graduate School, Nagoya University. Now at Kobe Works, Kobe Steel, Ltd., Nada-ku, Kobe 657.
} 


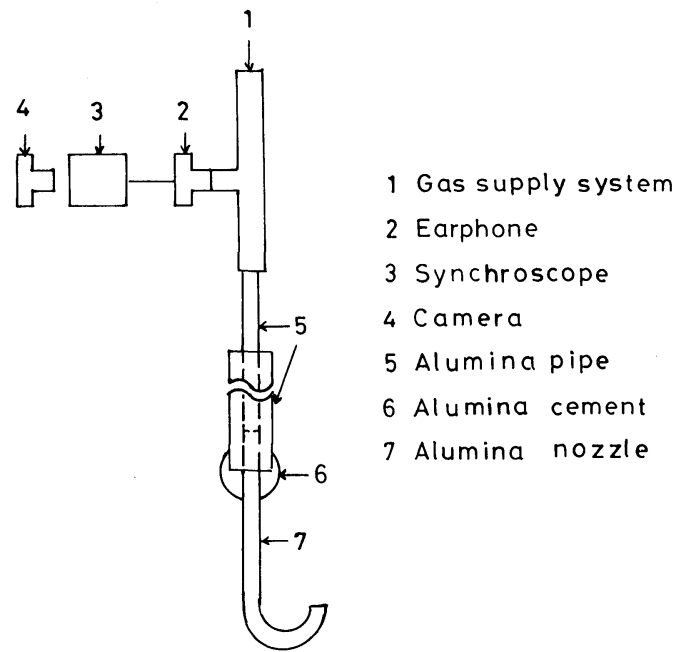

Fig. 2. Illustration of nozzle.

prevention of gas leakage, thin gap between the inner and outer pipes was filled with alumina cement. The nozzle was dried up and heated up to $1273 \mathrm{~K}$ for sintering.

After melting electrolytic iron under argon atmosphere, the nozzle was immersed down to the bottom of the melt. The oxygen concentration in the melt lower than $0.025 \%$ was controlled by blowing a mixture of $\mathrm{Ar}-\mathrm{H}_{2}$ and by adding an appropriate amount of carbon to the melt and deoxidizing the melt by $\mathrm{C}-\mathrm{O}$ reaction. In experiments for oxygen concentrations higher than $0.025 \%$ argon-oxygen mixture was injected into the melt to control the oxygen concentration. The sulfur concentration higher than that in the electrolytic iron $([\% \mathrm{~S}] \approx 0.005)$ was controlled by adding FeS to the melt.

The metal samples for chemical analysis were taken at suitable intervals by suction into an $0.25 \mathrm{~cm}$ I.D. silica tube and quenched in water. During each experiment of nitrogen absorption, the frequency of bubble formation was measured by the pressure pulse technique. The pressure pulse produced by the bubble formation was detected with a crystal earphone together with a synchroscope.

The mass of the melt $W_{F e}$ was $310 \sim 410 \mathrm{~g}$. The immersion depth of the nozzle $h$, that is the distance from the nozzle tip to the melt surface, was 3.3 $4.7 \mathrm{~cm}$. The nitrogen flow rate $V_{N_{2}}$ was $1.17 \sim$ $1.67 \mathrm{~cm}^{3} / \mathrm{s}$ in the standard state. The oxygen and sulfur concentrations were $0.0034 \sim 0.065$ and $0.0039 \sim$ $0.067 \%$, respectively. All the experiments were made at $1853 \mathrm{~K}$.

\section{Experimental Results}

\section{Preliminary Experiments}

Preliminary experiments were made to know the influence of nitrogen absorption through the free surface of the melt on the measured rate of absorption. The rates and efficiencies of nitrogen absorption with and without using the magnesia ring were com- pared in Fig. 3.

The nitrogen absorption efficiency $f$ is defined by

$$
\begin{aligned}
f & =\frac{\text { Amount of nitrogen absorbed per unit time }}{\text { Amount of nitrogen supplied per unit time }} \\
& =\frac{W_{F^{e} e}[\% \mathrm{~N}]_{S}}{100 M_{N_{2}}} \frac{\mathrm{d} \Theta}{\mathrm{d} t} /\left(\frac{V_{N_{2}}}{22400}\right) \ldots \ldots \ldots \ldots \ldots \ldots \ldots \ldots \ldots \ldots \ldots \ldots \ldots
\end{aligned}
$$

where, $\quad f$ : nitrogen absorption efficiency

$$
\begin{aligned}
W_{F e}: & \text { mass of iron }(\mathrm{g}) \\
M_{N_{2}}: & \text { molecular mass of nitrogen }(\mathrm{g} / \mathrm{mol}) \\
{[\% \mathrm{~N}]_{S}: } & \text { nitrogen concentration in molten iron } \\
& \text { in equilibrium with nitrogen pres- } \\
& \text { sure of } 1 \text { atm }(\text { mass } \%) \\
\Theta: \quad & \text { dimensionless nitrogen concentra- } \\
& \text { tion }\left(=[\% \mathrm{~N}] /[\% \mathrm{~N}]_{S}\right) \\
{[\% \mathrm{~N}]: \quad \text { nitrogen concentration in molten } } & \text { iron }(\operatorname{mass} \%) \\
t: \quad \text { time }(\mathrm{s}) & \text { nitrogen flow rate in the standard } \\
V_{N_{2}}: & \text { state }\left(\mathrm{cm}^{3} / \mathrm{s}\right) .
\end{aligned}
$$

Although the mass of iron is larger and the gasflow rate is smaller in the experiment (1) without using the ring than in the experiment (2) with using it, the change of nitrogen concentration with time in the former (1) is faster and hence the absorption efficiency is higher than in the latter (2). This indicates that the nitrogen absorption through the melt surface is not negligible, and the ring is effective in reducing the absorption through the melt surface.

Nextly, experiments were made to see if the absorption through the melt surface having the magnesia ring could be neglected. In the experiment (3), argon-nitrogen mixture was blown onto the surface. The composition of the gas mixture was changed with time so as to be in equilibrium with the nitrogen concentration in the melt.* In Fig. 4, the result is compared with that of experiment (4) without blowing onto the surface. There is some difference in the changes of nitrogen concentration with time. However, the difference arises from different experimental conditions of (3) and (4). This is evidenced by comparison of nitrogen absorption efficiency between the two experiments. Figure 4 clearly shows that the absorption efficiencies in the experiments (3) and (4)

* This concentration was estimated by a preliminary experiment. 

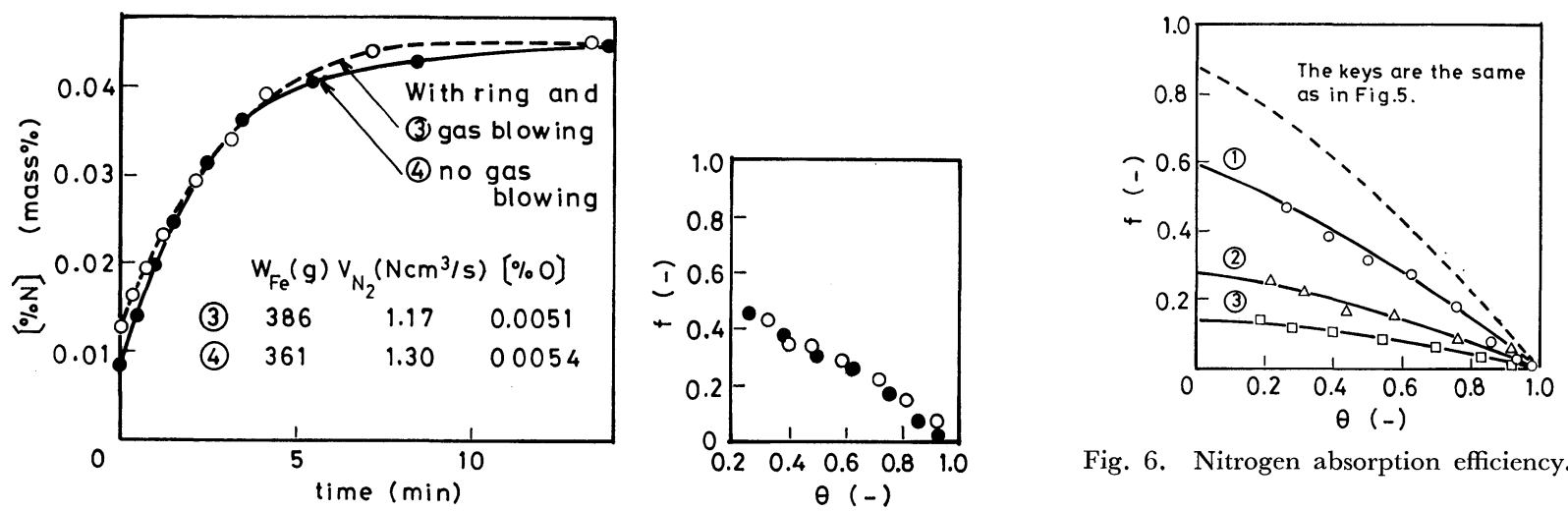

Fig. 6. Nitrogen absorption efficiency.

Fig. 4. Nitrogen absorption with and without blowing $\mathrm{Ar}-\mathrm{N}_{2}$ mixture onto melt surface.

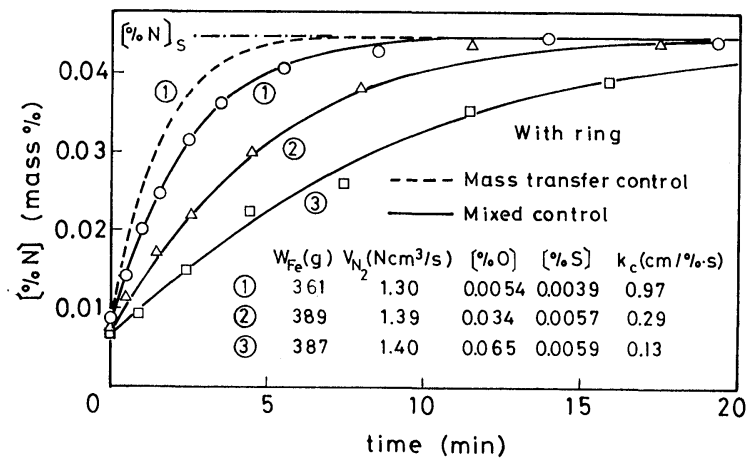

Fig. 5. Change of nitrogen concentration with time.

are almost the same. From the comparison, it may be permissible to state that the nitrogen absorption through the melt surface in the experiment with using the ring was negligible, even if the gas mixture was not blown onto the surface.*

All the results shown subsequently were obtained from experiments without surface blowing and with the ring.

\section{Change of Nitrogen Concentration with Time and Nitrogen Absorption Efficiency}

Figure 5 shows changes of nitrogen concentration with time for oxygen concentrations of $0.0054,0.034$ and $0.065 \%$. The sulfur concentration was kept nearly constant $([\% \mathrm{~S}]=0.0039 \sim 0.0059)$. It is seen from Fig. 5 that the absorption rate decreases with increasing oxygen concentration in the melt.

The nitrogen absorption efficiency was calculated from the experimental results shown in Fig. 5 and plotted against dimensionless nitrogen concentration $\Theta$ in Fig. 6. The absorption efficiency becomes lower with increasing oxygen concentration.

Figures 7 and 8 show the effect of sulfur on the nitrogen absorption in molten iron. As seen from the figures, sulfur in the melt lowers the rate and hence the efficiency of nitrogen absorption. Comparison between Fig. 6 and Fig. 8 suggests that on the basis of mass concentration oxygen has a greater influence

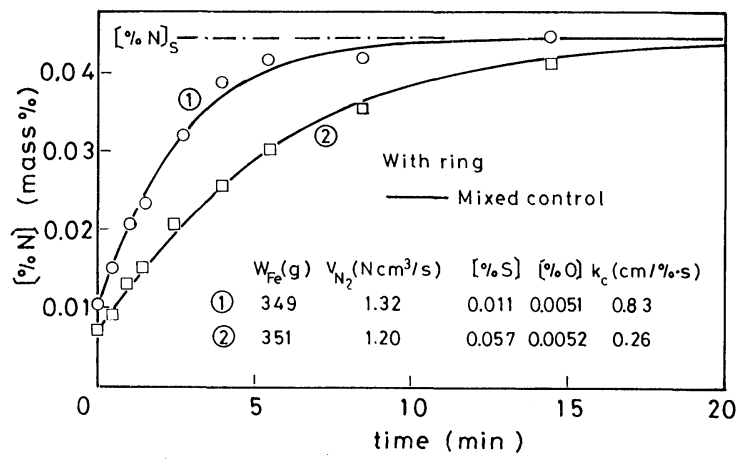

Fig. 7. Ghange of nitrogen concentration with time.

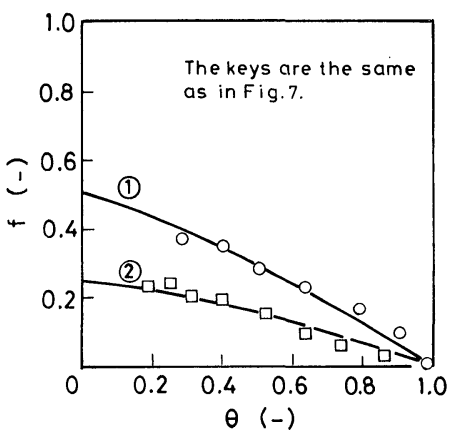

Fig. 8. Nitrogen absorption efficiency.

on the absorption rate than sulfur.

The effect of surface active elements on the molten iron-nitrogen reaction through the bubble interface shown in Figs. 5 to 8 is similar to that through the planar surface. ${ }^{4-6}$ )

\section{Bubble Formation Time}

Knowledge on the area of the bubble-metal interface is indispensable to analyse the experimental results of absorption rate of nitrogen injected into molten iron. Therefore, the frequency of bubble formation was measured during each absorption experiment.

Photograph 1 shows an example of pressure pulses of bubble formation detected by a crystal earphone. The formation of a bubble produces one pulse. Hence, the bubble frequency can be determined from

* This may be due to the reduction of the free surface area by placing the ring on the surface and to the gradual increase of nitrogen pressure in the atmosphere as a result of mixing of argon in the furnace and unabsorbed nitrogen detached from the surface. 


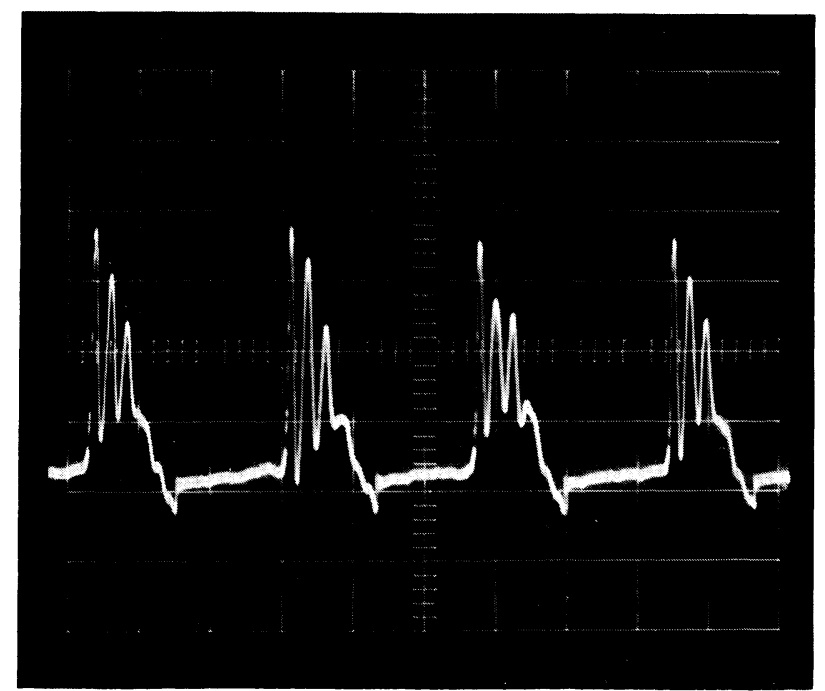

$20 \mathrm{~ms} / \mathrm{div}, 10 \mathrm{mV} / \mathrm{div}$

$V_{N_{2}}=1.39 \mathrm{Ncm}^{3} / \mathrm{s}, \quad h=4.5 \mathrm{~cm}$

$[\% \mathrm{O}]=0.011,[\% \mathrm{~S}]=0.004$

$\tau=1853 \mathrm{~K}, f_{B}=18.4 \mathrm{bubble} / \mathrm{s}$

Photo. 1. Variation of pressure in gas supply train during bubble formation.

the distance between two adjacent peaks.

The bubble formation time $t_{f}(\mathrm{~s})$ which is the reverse of bubble frequency $f_{B}\left(\mathrm{~s}^{-1}\right)$ is plotted in Fig. 9. It is seen that the bubble formation time is independent of the nitrogen concentration in the melt. If the nitrogen absorption during bubble formation is neglected, the volume of a bubble formed at the nozzle $V_{B}\left(\mathrm{~cm}^{3}\right)$ can be calculated from the following equation.

$$
V_{B}=V_{N_{2}}^{\prime} / f_{B}
$$

where, $V_{N_{2}}^{\prime}$ : nitrogen flow rate at $1853 \mathrm{~K}\left(\mathrm{~cm}^{3} / \mathrm{s}\right)$.

The bubble diameter is calculated on the assumption that the bubble is spherical. Under the present experimental conditions, the bubble diameter was $0.92 \sim 1.08 \mathrm{~cm}$.

Previously, the authors obtained a correlation for the diameter of bubbles formed from a nozzle immersed in molten iron. ${ }^{2)}$ The bubble diameter calculated from the correlation for a nozzle of $0.3 \mathrm{~cm}$ in outer diameter was $0.86 \sim 0.96 \mathrm{~cm} .{ }^{*}$ The calculated value is somewhat smaller than the experimental one. The difference comes from a nonnegligible influence of gas chamber on the bubble formation in the present experiment. $* * 1)$

Hence, the bubble formation time measured during each absorption experiment is used for the kinetic analysis of molten iron-nitrogen reaction through the bubble interface.

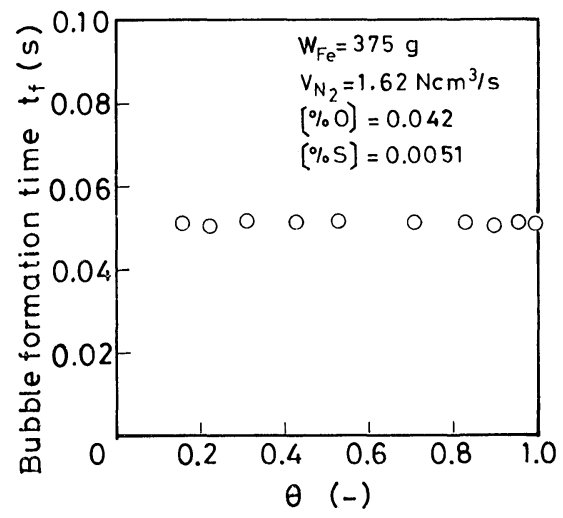

Fig. 9. Bubble formation time.

\section{Discussion}

The absorption rate of nitrogen injected into molten iron is theoretically calculated by a mixed control model of liquid-phase mass transfer and chemical reaction at the bubble interface.*** On the basis of the comparison between the theoretical calculation and the experimental result, the reaction mechanism of nitrogen absorption in molten iron and the effect of oxygen and sulfur in the melt on the absorption rate are discussed.

\section{Reaction Model}

1. Reaction Model for Nitrogen Absorption during Bubble Ascent in Molten Iron

The change of mole of nitrogen in a rising bubble with time is given by

$$
\begin{aligned}
-\frac{\mathrm{d} n_{N_{2}}}{\mathrm{~d} t} & =k_{C} A\left(K^{2} P_{N_{2}}-[\% \mathrm{~N}]_{i}^{2}\right) \frac{\rho_{F e}}{100 M_{N_{2}}} \\
& =k_{L} A\left([\% \mathrm{~N}]_{i}-[\% \mathrm{~N}]\right) \frac{\rho_{F e}}{100 M_{N_{2}}}
\end{aligned}
$$

where, $\quad n_{N_{2}}$ : mole of nitrogen in a bubble (mol)

$A$ : bubble-metal interfacial area $\left(\mathrm{cm}^{2}\right)$

$K$ : equilibrium constant of molten ironnitrogen reaction $\left(=\left([\% \mathrm{~N}] / \sqrt{ } P_{N_{2}}\right)_{e}\right)$ (mass $\% / a^{1 / 2}$ )

$[\% \mathrm{~N}]_{i}:$ nitrogen concentration at the bubble interface $(\operatorname{mass} \%)$

$P_{N_{2}}$ : nitrogen pressure in bubble (atm)

$k_{C}$ : chemical reaction rate constant $(\mathrm{cm} / \% \cdot \mathrm{s})$

$k_{L}$ : liquid-phase mass transfer coefficient (Higbie's equation)

$$
\left(=2 \sqrt{ } D_{N} v_{B} /\left(\pi d_{B}\right)\right)(\mathrm{cm} / \mathrm{s})
$$

$\rho_{F^{\prime} e}$ : density of molten iron $\left(\mathrm{g} / \mathrm{cm}^{3}\right)$

$D_{N}$ : diffusivity of nitrogen in molten iron $\left(\mathrm{cm}^{2} / \mathrm{s}\right)$

* The surface tension of molten iron measured by Kozakevitch et al ${ }^{10)}$ was used in the calculation.

** The correlation was obtained under the condition that the gas chamber did not affect the bubble formation.

*** Here, 'chemical reaction' is a general name for the several possible rate-determining steps at the bubble interface, such as adsorption, chemical reaction and desorption.

Since the bubble diameter in the present experiment is relatively large, movement at the bubble-metal interface is not affected by adsorption of surface active elements. It is presumed that the liquid-phase mass transfer coefficient does not change much with the oxygen and sulfur concentrations in the melt. 
$v_{B}:$ bubble rising velocity $\left(=\sqrt{ } 0.5 d_{B} g\right)$ $(\mathrm{cm} / \mathrm{s})$

$d_{B}:$ bubble diameter $(\mathrm{cm})$

$g$ : acceleration of gravity $\left(\mathrm{cm} / \mathrm{s}^{2}\right)$.

The nitrogen concentration at the bubble interface $[\% \mathrm{~N}]_{i}$ is given by

$$
[\% \mathrm{~N}]_{i}=\frac{-k_{L}+\sqrt{k_{L}^{2}+4 k_{C}\left(k_{L}[\% \mathrm{~N}]+k_{C} K^{2} P_{N_{2}}\right)}}{2 k_{C}}
$$

The bubble-metal interfacial area $A$, the bubble diameter $d_{B}$ and the pressure in the bubble $P_{N_{2}}$ are calculated from

$$
\begin{aligned}
& A=\pi d_{B}^{2} \\
& d_{B}=\left\{6 n_{N_{2}} R T /\left(\pi P_{N_{2}}\right)\right\}^{1 / 3} \\
& P_{N_{2}}=P_{o}+\rho_{F e} g(h-x) /\left(1.013 \times 10^{6}\right)
\end{aligned}
$$

where, $R:$ gas constant $\left(\mathrm{cm}^{3} \cdot \operatorname{atm} /(\mathrm{mol} \cdot \mathrm{K})\right)$

$T:$ melt temperature $(\mathrm{K})$

$P_{o}:$ atmospheric pressure (atm)

$h$ : vertical distance from the nozzle tip to the melt surface $(\mathrm{cm})$

$x$ : vertical distance from the nozzle tip (cm).

By using the correlations shown above, Eq. (2) is transformed into

$$
\begin{gathered}
-\frac{\mathrm{d} n_{N_{2}}}{\mathrm{~d} x}=\alpha n_{N_{2}}^{5 / 12} P_{O}^{1 / 12}\left(\Theta_{i}-\Theta\right) \ldots \ldots \ldots \ldots \ldots \ldots \\
\alpha \equiv 2 \sqrt{\pi D_{N} \sqrt{\frac{2}{g}}}\left(\frac{6 R T}{\pi}\right)^{5 / 12} \frac{\rho_{F e}}{100 M_{N_{2}}} K
\end{gathered}
$$

Application of the boundary condition of $n_{N_{2}}=n_{0}$ at $x=0$ to Eq. (7) gives the following result for the mole of nitrogen $n_{N_{2}}$ in the bubble leaving the melt surface.*

$$
n_{N_{2}}=\left\{n_{0}^{7 / 12}-(7 / 12) \alpha P_{0}^{1 / 12} h\left(\Theta_{i}-\Theta\right)\right\}^{12 / 7}
$$

The mole of nitrogen $n_{a}$ absorbed during bubble ascent is given by

$$
n_{a}=n_{0}-n_{N_{2}}
$$

\section{Reaction Model for Nitrogen Absorption during Bubble}

\section{Formation}

It has been demonstrated for molten silver-oxygen reaction that the amount of mass transfer during bubble formation is very large. ${ }^{3)}$ In the present theoretical consideration, the additional contribution of mass transfer during bubble formation is estimated by using a model proposed by Groothius and Kramers. ${ }^{11)}$

According to the model, the mole of nitrogen $n_{f}$ absorbed during bubble formation is

$$
n_{f}=1.52 \sqrt{\pi D_{N}} d_{B o}^{2} t_{f}^{1 / 2} K \sqrt{P_{N_{2}}}\left(\Theta_{i, a v}-\Theta\right) \rho_{F e} / 100 M_{N_{2}}
$$

where, $d_{B O}$ : diameter of bubble at detachment from the nozzle $(\mathrm{cm})$

\author{
$t_{f}:$ bubble formation time (s) \\ $\Theta_{i, a v}:$ average dimensionless nitrogen con- \\ centration at the bubble interface.
}

In deriving Eq. (11), the decrease of bubble diameter due to the absorption is neglected,** and $\left(\Theta_{i, a v}\right.$ $-\Theta)$ is assumed to be constant. Hence, $\Theta_{i, a v}$ is obtained by using Eq. (11) and the following equation.

$$
\begin{aligned}
n_{f} & =\int_{0}^{t_{f}} k_{C} A(t)\left(K^{2} P_{N_{2}}-[\% \mathrm{~N}]_{i, a v}^{2}\right) \frac{\rho_{F e}}{100 M_{N_{2}}} \mathrm{~d} t \\
& =\frac{3}{5} k_{C} \pi d_{B o}^{2} t_{f} K^{2} P_{N_{2}}\left(\Theta_{s}^{2}-\Theta_{i, a v}^{2}\right) \frac{\rho_{F^{\prime} e}}{100 M_{N_{2}}} \cdots
\end{aligned}
$$

where, $A(t)$ : surface area of a bubble forming at the nozzle $\left(\mathrm{cm}^{2}\right)$.

Thus, $\Theta_{i, a v}$ becomes

$$
\begin{aligned}
& \Theta_{i, a v}=\frac{-\beta+\sqrt{\beta^{2}+4\left(\Theta_{s}^{2}+\beta \Theta\right)}}{2} \\
& \beta \equiv \frac{7.6}{3} \frac{1}{k_{C} K \sqrt{P_{N_{2}}}} \sqrt{\frac{D_{N}}{\pi t_{f}}}
\end{aligned}
$$

\section{Method of Calculation}

The total mole of nitrogen absorbed during bubble formation and ascent is obtained by using Eqs. (10) and (11). Thus the absorption efficiency $f$ can be calculated from

$$
f=\left(n_{f}+n_{a}\right) / n_{t}
$$

where, $n_{t}:$ mole of nitrogen injected into molten iron during bubble formation ( $\mathrm{mol}$ ).

The theoretical efficiency of nitrogen absorption is used to calculate the change of the nitrogen concentration with time. The time $\left(t_{j+1}-t_{j}\right)$ required to increase the dimensionless nitrogen concentration from $\Theta_{j}$ to $\Theta_{j+1}\left(=\Theta_{j}+0.002\right)$ is calculated from Eq. (16) successively.

$$
t_{j+1}-t_{j}=\frac{22400}{V_{N_{2}}} \frac{W_{F e}}{100 M_{N_{2}}}[\% \mathrm{~N}]_{s} \frac{\Theta_{j+1}-\Theta_{j}}{f_{j+1, j}}
$$

where, $\Theta_{j}:$ dimensionless nitrogen concentration at time $t_{j}$

$f_{j}:$ nitrogen absorption efficiency for $\Theta=\Theta_{j}$ $f_{j+1, j}: \quad\left(f_{j}+f_{j+1}\right) / 2$.

The following values are used in the calculation.

$$
\begin{aligned}
& \rho_{F e}=7 \mathrm{~g} / \mathrm{cm}^{3} \\
& K=0.0447 \mathrm{mass} \% / \mathrm{atm}^{1 / 2} \\
& \left.D_{N}=0.9 \times 10^{-4} \mathrm{~cm}^{2} / \mathrm{s}^{12}\right)
\end{aligned}
$$

Several experimental values of nitrogen diffusivity in molten iron have been obtained $\left(D_{N}=0.5 \times\right.$ $\left.10^{-4} \mathrm{~cm}^{2} / \mathrm{s}^{13)}-1.1 \times 10^{-4} \mathrm{~cm}^{2} / \mathrm{s}^{14)}\right)$. Since Inouye et al. ${ }^{12)}$ examined the experimental conditions and results in detail, their value of $D_{N}$ is adopted in the calculation.

The chemical reaction rate constant $k_{C}$ is determined by the trial and error method. Figure 10 shows an example of determination of $k_{C}$. As can be seen from the figure, when the oxygen and sulfur concentrations in the melt are low, the calculated

* The condition $P_{O} \gg \rho_{F e} g(h-x) / 1.013 \times 10^{6}$ is used for deriving Eqs. (7) and (9).

** The maximum error in $d_{B}$ caused by the assumption is about $3 \%$. 


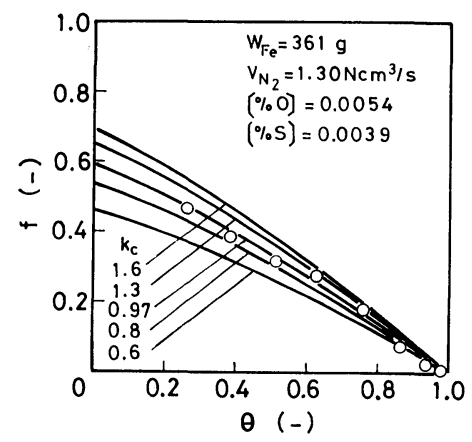

Fig. 10. Determination of chemical reaction rate constant $k_{C}$.

nitrogen absorption efficiency does not change much with the value of chemical reaction rate constant $k_{C}$. On the other hand, as shown later in $I V .4$, the determined $k_{C}$ depends largely on the value of nitrogen diffusivity used in the calculation. Therefore, it is difficult to determine $k_{C}$ accurately.* From comparison between calculated and experimental values in Fig. $10, k_{C}$ is determined to be roughly equal to $0.97 \mathrm{~cm} / \% \cdot \mathrm{s}$.

\section{Comparison between Experiments and Calculations}

The change of nitrogen concentration with time and the nitrogen absorption efficiency are calculated theoretically by using $D_{N}=0.9 \times 10^{-4} \mathrm{~cm}^{2} / \mathrm{s}$ and compared with experimental ones in Figs. 5 to 8 . The dotted lines in Figs. 5 and 6 correspond to the theoretical values for the experimental conditions of (1) calculated on the assumption of $k_{C} \rightarrow \infty$, that is liquidphase mass transfer control. As can be seen from the figures, the absorption rate and efficiency are higher than the experimental ones. This is also true for $D_{N}=0.5 \times 10^{-4} \mathrm{~cm}^{2} / \mathrm{s}$.

Thus, it is clear that even at low oxygen and sulfur concentrations, the rate of nitrogen absorption in molten iron is controlled both by liquid-phase mass transfer and by chemical reaction at the bubble interface. The solid lines in Figs. 5 to 8, show the calculations from the mixed control model. The chemical reaction rate constants described in Figs. 5 and 7 are obtained from comparison between the experimental result and the calculation in which $D_{N}=$ $0.9 \times 10^{-4} \mathrm{~cm}^{2} / \mathrm{s}$ is used.

\section{Contribution of Nitrogen Absorption during Bubble Formation}

In the present experiments, the bubble formation time was $0.05 \sim 0.07 \mathrm{~s}$, and the bubble diameter was about $1 \mathrm{~cm}$. For a bubble of this size, the rising velocity is calculated to be $22 \mathrm{~cm} / \mathrm{s}$, and hence the residence time of the bubble in the melt becomes $0.15 \sim 0.21 \mathrm{~s}$. It is noted that the bubble formation time is not negligible as compared with the residence time.

The calculations show that the ratio of the amount of nitrogen absorbed during bubble formation to

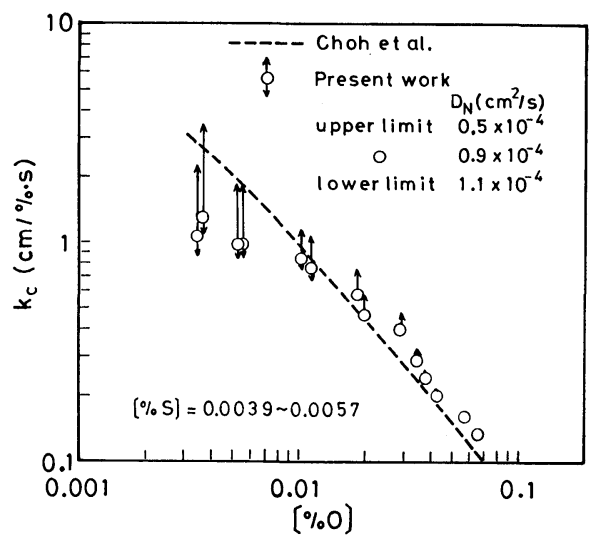

Fig. 11. Relation between chemical reaction rate constant $k_{C}$ and oxygen concentration.

the total amount of nitrogen absorbed during bubble formation and ascent is $0.15 \sim 0.22$. This suggests that under the present experimental conditions the nitrogen absorption during bubble formation should be taken into account.

\section{Dependence of Chemical Reaction Rate Constant on Oxygen and Sulfur Concentrations in the Melt}

Figure 11 shows the chemical reaction rate constant $k_{C}$ obtained by varying the oxygen concentration from 0.0034 to $0.065 \%$ and keeping the sulfur concentration almost constant (0.0039 0.0057\%). The value of $k_{C}$ represented by a circle is obtained by using $D_{N}=0.9 \times 10^{-4} \mathrm{~cm} / \mathrm{s}$ and the values of $k_{C}$ at the upper and lower limits of the arrows are obtained by using $D_{N}=0.5 \times 10^{-4}$ and $1.1 \times 10^{-4} \mathrm{~cm}^{2} / \mathrm{s}$.

As seen from Fig. 11, in the range of $[\% \mathrm{O}]>\sim$ $0.015 k_{C}$ is in reverse proportion to $[\% \mathrm{O}]$, while in the lower range of $[\% \mathrm{O}] k_{C}$ tends to approach to a constant value. The variation of $k_{C}$ with $D_{N}$ is very small at high $[\% \mathrm{O}]$ and becomes larger with decreasing $[\% \mathrm{O}]$. This is due to the fact that at high $[\% \mathrm{O}]$ the absorption rate is almost controlled by chemical reaction, and with decreasing $[\% \mathrm{O}]$ the resistance of chemical reaction becomes smaller.

Choh and Inouye ${ }^{15)}$ studied nitrogen desorption from the free surface of molten iron of various oxygen concentrations under reduced pressures. The dotted line in Fig. 11 shows their result. It is to be noted that the present result roughly agrees with that of Choh et al. A study of desorption of nitrogen by argon injected into molten iron is now being made to know the mechanism of molten iron-nitrogen reaction in more detail.

Figure 12 shows the influence of sulfur concentration in the melt on the chemical reaction rate constant. In the experiments, the sulfur concentration was varied between $0.0039 \%$ and $0.067 \%$, the oxygen concentration being kept roughly constant $(0.0034 \sim 0.0063 \%)$. As seen from the figure, $k_{C}$ is in reverse proportion to $[\% \mathrm{~S}]$ in the range of $[\% \mathrm{~S}]>$ $0.01 \sim 0.02$.

\footnotetext{
* Since at a high oxygen or sulfur concentration the absorption rate is almost controlled by chemical reaction, $\kappa_{C}$ can be determined more accurately.
} 


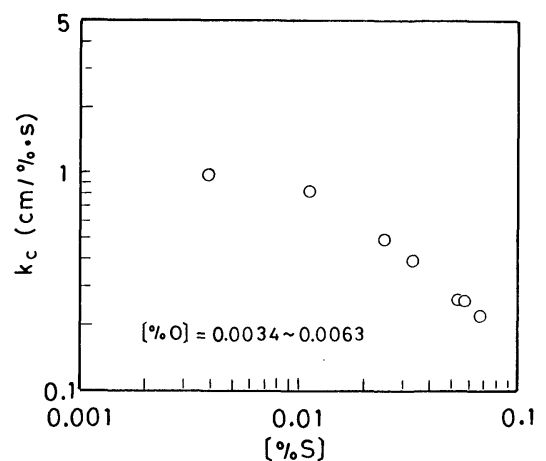

Fig. 12. Relation between chemical reaction rate constant $k_{C}$ and sulfur concentration.

It is interesting to know how the chemical reaction rate constant changes with concentrations of both oxygen and sulfur. The reaction rate constants shown in Figs. 11 and 12 together with those obtained by varying both oxygen and sulfur concentrations are plotted against $[\% \mathrm{O}]+[\% \mathrm{~S}] / 2$ in Fig. 13. It was found that the reaction rate constant for various oxygen and sulfur concentrations can be expressed as a function of $[\% \mathrm{O}]+[\% \mathrm{~S}] / 2$.

\section{Comparison of Molten Iron-Nitrogen Reaction through the Bubble Interface and through the Melt Surface}

Previously, it was shown that while the rate of molten silver-oxygen reaction through the bubble interface is controlled by liquid-phase mass transfer, ${ }^{3)}$ that through the free surface is controlled both by chemical reaction at the surface and liquid-phase mass transfer. ${ }^{9)}$ It is presumed that the difference in the reaction mechanism is due to the presence of thin oxide film on the melt surface.*

Figure 11 shows that in the case of molten ironnitrogen reaction, the chemical reaction rate constant for the bubble interface agrees with that for the free surface. From this it follows that there is no particular difference between the bubble interface and the free surface of melt. It is presumed that there is no oxide film on the surface of iron melt.

Kozakevitch et al. ${ }^{7)}$ made an experiment of absorption of nitrogen injected into molten iron and obtained volumetric first-order rate constants $k_{1}^{\prime} A$. The volumetric constant decreased markedly with increasing oxygen concentration. However, the effect of sulfur on the volumetric constant was much smaller than that of oxygen. This is not in accordance with the present finding.

\section{Apparent First-order Rate Constant (Apparent Mass Transfer Coefficient)}

As in the case of nitrogen absorption through the free surface of iron melt, the present experimental result is plotted according to the first-order rate equation to obtain an apparent first-order rate constant.

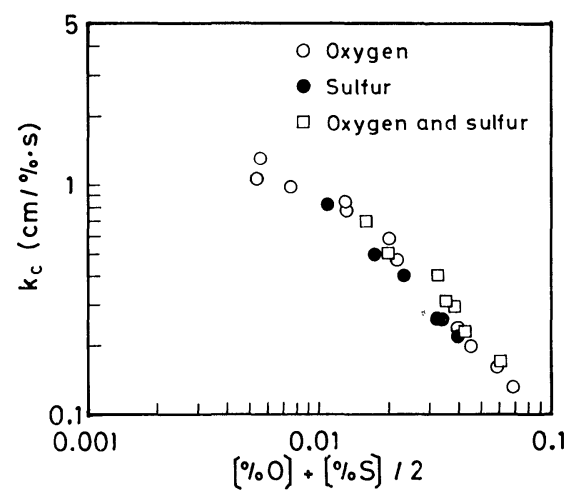

Fig. 13. Relation between chemical reaction rate constant $k_{C}$ and $[\% \mathrm{O}]+[\% \mathrm{~S}] / 2$.

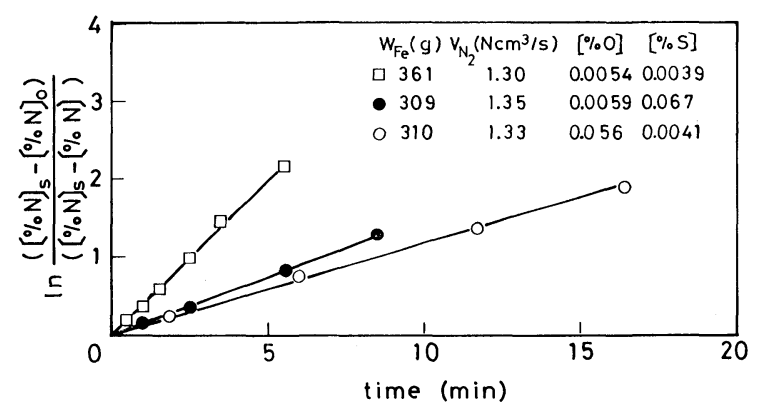

Fig. 14. First-order plot of nitrogen absorption in molten iron.

$$
\frac{\mathrm{d}[\% \mathrm{~N}]}{\mathrm{d} t}=k_{1}^{\prime} \frac{A}{V}\left([\% \mathrm{~N}]_{s}-[\% \mathrm{~N}]\right)
$$

where, $k_{1}^{\prime}$ : apparent first-order rate constant (apparent mass transfer coefficient) $(\mathrm{cm} / \mathrm{s})$

$A$ : total area of bubble-metal interface $\left(\mathrm{cm}^{2}\right)$

$V$ : volume of iron melt $\left(\mathrm{cm}^{3}\right)$.

In Fig. $\left.14 \ln \left\{\left([\% \mathrm{~N}]_{s}\right)-[\% \mathrm{~N}]_{0}\right) /\left([\% \mathrm{~N}]_{s}-[\% \mathrm{~N}]\right)\right\}$ $\left([\% \mathrm{~N}]_{0}\right)$ : initial nitrogen concentration $\left.(\operatorname{mass} \%)\right)$ is plotted against $t$. It is seen that the present rate data apparently fit the first-order rate law, although the absorption rate is controlled both by liquid-phase mass transfer and by chemical reaction. One can obtain $k_{1}^{\prime}(A / V)$ from the slope of the straight line in Fig. 14 .

On the basis of the mixed control model of liquidphase mass transfer and chemical reaction, $k_{1}^{\prime}$ is expressed as

$$
k_{1}^{\prime}=\frac{k_{C}}{k_{C} / k_{L}+1 /\left([\% \mathrm{~N}]_{s}+[\% \mathrm{~N}]_{i}\right)}
$$

In Fig. 15, the value of $k_{1}^{\prime}$ calculated from Eq. (18) for a bubble diameter of $1 \mathrm{~cm}$ is plotted against the nitrogen concentration $[\% \mathrm{~N}]$ in the melt. Figure 15 indicates that $k_{1}^{\prime}$ does not change much with $[\% \mathrm{~N}]$. This gives the reason why the absorption rate of nitrogen in molten iron fits the first-order rate law.

Thus, it is shown that the change of nitrogen concentration in the melt in practical injection processes

\footnotetext{
* Glen and Richardson ${ }^{16)}$ found that the oxidation of a levitated drop of molten copper by a mixture of oxygen and nitrogen was impeded by thin silica film on the surface.
} 


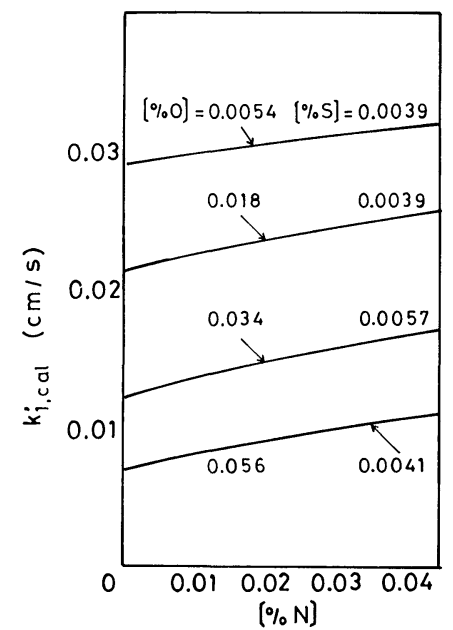

Fig. 15. Relation between calculated apparent first-order rate constant $k_{1}^{\prime}$ and nitrogen concentration in molten iron.

can be calculated using the apparent first-order rate constant and the total bubble-metal interfacial area A.

\section{Conclusion}

The absorption rate of nitrogen injected through a nozzle immersed in molten iron was measured and compared with the calculated result from a mixed control model. The findings in the present study are summarized as follows:

(1) The rate of absorption of nitrogen injected into molten iron is controlled by liquid-phase mass transfer and chemical reaction at the bubble interface.

(2) The chemical reaction rate constant $k_{C}$ can be correlated as a function of $[\% \mathrm{O}]+[\% \mathrm{~S}] / 2$. The rate constant decreases with increasing $[\% \mathrm{O}]+$ $[\% \mathrm{~S}] / 2$.

(3) The rate constant $k_{C}$ for the bubble interface roughly agrees with that for the free surface of melt.

(4) The apparent first-order rate constant for absorption of nitrogen in molten iron does not change much with nitrogen concentration in the melt.

\section{REFERENGES}

1) M. Sano and K. Mori: Trans. JIM, 17 (1976), 344.

2) K. Mori, M. Sano and T. Sato: Trans. ISIJ, 19 (1979), 553.

3) M. Sano and K. Mori: Trans. JIM, 23 (1982), 440.

4) M. Inouye and T. Choh: Trans. ISIJ, 8 (1968), 134.

5) K. Mori and K. Suzuki: Trans. ISIJ, 10 (1970), 232.

6) S. Ban-ya, T. Shinohara, H. Tozaki and T. Fuwa: Tetsuto-Hagané, 60 (1974), 1443.

7) P. Kozakevitch and G. Urbain: Mem. Sci. Rev. Met., 60 (1963), 143.

8) R. J. Fruehan: Met. Trans., 6B (1975), 573.

9) K. Mori, M. Sano and K. Suzuki: Trans. ISIJ, 13 (1973), 64.

10) P. Kozakevitch and G. Urbain: Mem. Sci. Rev. Met., 58 (1961), 519.

11) H. Groothius and H. Kramers: Chem. Eng. Sci., 4 (1955), 17.

12) M. Inouye, Y. Kojima, T. Choh, S. Uekawa and $Y$. Yamada: Tetsu-to-Hagané, 59 (1973), 205.

13) N. M. El-Tayeb and N.A.D. Parlee: Trans. Met. Soc. AIME, 239 (1967), 2010.

14) K. Schwerdtfeger: Trans. Met. Soc. AIME, 239 (1967), 134.

15) T. Choh, T. Moritani and M. Inouye: Tetsu-to-Hagané, 64 (1978), 701.

16) G. G. Glen and F. D. Richardson: Heterogeneous Kinetics at Elevated Temperature, ed. by G. R. Belton and W. L. Worrell, Plenum Press, New York, (1970), 369. 